\title{
Morphological Characterization of Terminalia chebula Retz. in Sri Lanka
}

\author{
T.A.B.D. Sanjeewa ${ }^{*}$, D.K.N.G. Pushpakumara ${ }^{1}$ and U.R. Sangakkara ${ }^{1}$ \\ Postgraduate Institute of Agriculture \\ University of Peradeniya \\ Sri Lanka.
}

\begin{abstract}
Terminalia chebula Retz. (Aralu in Sinhala) is a perennial plant, which consists of vital medicinal properties. The $\underline{T}$. chebula trees are naturally distributed only in the Intermediate Zone of Sri Lanka, although planted trees can be seen in all agro-climatic zones. However, no agronomic or ecological research has been conducted on this species. Consequently, this research was conducted to identify the ecological distribution of $\underline{T}$. chebula in different agro-ecological regions of Sri Lanka and to characterize the different populations based on its morphological variation. Forty one morphological characters were considered using samples from 125 trees representing different populations. The studied populations in Sri Lanka could be clustered into 4 groups based on their morphological characters. Each group consisted of plants from different locations, which suggest that the grouping is not based on environmental parameters. However, $80 \%$ of the Nilgala population grouped into one cluster and all the natural $\underline{\text { T. }}$ chebula plants are located only in Intermediate Zone indicating a relationship between the plant and the environmental parameters under natural conditions.
\end{abstract}

Keywords: Cluster analysis, ecological distribution, morphological characterization, principle component analysis, Terminalia chebula

\section{INTRODUCTION}

Terminalia chebula Retz. (Aralu in Sinhala) is a perennial medicinal plant belonging to the family Combretaceae. Various parts of the plant have vital medicinal properties and are used extensively in indigenous and ayurvedic medicinal systems. It is relatively rare in Sri Lanka when compared to other Terminalia species (Ayurveda Department, 2002).

Due to the vital medicinal properties, it is listed in 50 extensively used medicinal plant species in Sri Lanka (Handa et al., 2006). Further, there are no agronomic and ecological research conducted on this plant, although there are several research on its medicinal value (Ayurveda Department, 2002). Thus, the objective of this study was to identify T. chebula populations in Sri Lanka and their morphological characterization.

\footnotetext{
1 Department of Crop Science, Faculty of Agriculture, University of Peradeniya, Sri Lanka

* Corresponding author: tabsanjeewa@gmail.com
} 


\section{MATERIALS AND METHODS}

\section{Research locations/sites}

Locations of T. chebula plants/populations were identified using literature (Philcox, 1997), and information given by the officials of the Departments of Forest, Wildlife Conservation and Indigenous Medicine, and the general public. Thereafter, the sites for sampling were determined based on distribution of populations in different agro-ecological regions and their relative importance. Sampled sites/trees were classified as natural and planted based on the characters of their locations and populations.

\section{Sampling procedure}

In natural populations, 10-30 trees were sampled. In order to identify the variations within and between populations, a tree cluster of 5-6 trees were selected within a population. A distance of at least $1 \mathrm{~km}$ was maintained between clusters. The identified characters in all sampled individuals were observed and recorded, and samples of other plant parts were collected. All trees from cultivated sites were observed for morphological characters and sampled. From each sampled tree, 25 leaves, 5-25 flowers and 5-25 fruits were taken for the analysis of morphological characters. The secondary data with respect to each agroecological region on Rainfall pattern, $\mathrm{RH}$, temperature and soil type were extracted from published reports (Punyawardena, 2008).

\section{Variables used for morphological characterization}

Seven tree characters, 3 bark characters, 16 leaf characters, 5 flower characters, 10 fruit characters and 8 environmental parameters were measured (parametric variables) or scored (non-parametric variables) to analyze the morphological variation of the sample. The morphological data and environmental parameters assessed during the study were identified, measured and recorded as proposed by the IBPGR (1980).

\section{Data analysis}

The data were subjected to Principal Component Analysis (PCA) and those PCAs with eigen values greater than 1.00 were selected. Cluster Analysis was used to identify groups of objects that are similar (Sneath and Sokal, 1973). The dendrogam was obtained by hierarchical clustering of the first three principal components using the Ward Linkage Method (Ward, 1963). Environmental factors and climatic data were also correlated with morphological parameters to explain the final dendrogram obtained from Cluster Analysis. Data analysis was conducted using SAS Statistical Software (SAS, 2004).

\section{RESULTS AND DISCUSSION}

\section{Ecological distribution of Terminalia chebula in Sri Lanka}

Terminalia chebula trees are naturally distributed only in the intermediate zone of Sri Lanka. However, planted trees were observed in all agro-ecological zones. The locations of sampled and non-sampled natural populations as well as planted trees of T. chebula, their agroecological regions and related site information are presented in Table 1. 
Based on the pattern of distribution, it is clear that environmental conditions of the Intermediate zone of Sri Lanka are mainly suitable for growth and natural reproduction of $T$. chebula plants. Plants can thrive in other areas however, only with human influence on seed germination/propagation. Natural regeneration was not observed under any of the planted trees although, natural regeneration was observed in natural $T$. chebula populations.

Table 1: Ecological distribution of Terminalia chebula populations in Sri Lanka.

\begin{tabular}{|c|c|c|c|c|}
\hline Sampled location & $\begin{array}{l}\text { Agro-ecological } \\
\text { region }\end{array}$ & $\begin{array}{c}\text { Elevation } \\
\text { m amsl }\end{array}$ & $\operatorname{GPS}^{0} \mathbf{N}$ & $\operatorname{GPS}^{0} \mathbf{E}$ \\
\hline \multicolumn{5}{|l|}{ Natural trees } \\
\hline Dambana & IL2 & 187 & 7.399 & 81.101 \\
\hline SandasiriDunuwila\& & IM3c & 856 & 7.239 & 80.835 \\
\hline \multicolumn{5}{|l|}{ Moragahamula } \\
\hline Puwakpitiya in & IM1b & 435 & 7.580 & 80.740 \\
\hline \multicolumn{5}{|l|}{ Laggala } \\
\hline Lunugala & IM2b & 830 & 7.00 & 80.77 \\
\hline Bulupitiya & IL2 & 223 & 7.225 & 81.352 \\
\hline Nilgala & IL2 & 250 & 7.224 & 81.313 \\
\hline Belihuloya & $\mathrm{IM} 2 \mathrm{~b}$ & 636 & 6.715 & 80.784 \\
\hline \multicolumn{5}{|l|}{ Planted trees } \\
\hline Mihintale & DL1b & 108 & 8.360 & 80.508 \\
\hline Galpalama & DL1b & 95 & 8.353 & 80.414 \\
\hline Navinna & WL3 & 07 & 6.934 & 79.850 \\
\hline Ganewaththa & IL3/IL1b & 119 & 7.653 & 80.337 \\
\hline Dewalegama & WL2b & 180 & 7.283 & 80.344 \\
\hline Peradeniya & WM2b & 486 & 7.268 & 80.595 \\
\hline \multicolumn{5}{|l|}{ Non sampled locations* } \\
\hline Natural trees & \multicolumn{4}{|c|}{ Planted trees } \\
\hline Location & $\begin{array}{c}\text { Agro ecological } \\
\text { region }\end{array}$ & Location & & $\begin{array}{l}\text { Agro } \\
\text { ecological } \\
\text { region }\end{array}$ \\
\hline Maligawila & IL1c & \multirow{2}{*}{\multicolumn{2}{|c|}{$\begin{array}{l}\text { Haldummulla, } \\
\text { Mapalana (Ruhuna } \\
\text { University) }\end{array}$}} & IU3b \\
\hline Meegahakiwula & IL2/IM1c & & & IL1a \\
\hline Padiyathalawa & IL2 & \multicolumn{2}{|c|}{ Hikkaduwa } & WL2a \\
\hline Wellawaya & IL1c & \multicolumn{2}{|c|}{ Endana in Rathnapura } & WM1a \\
\hline Buththala & IL1c & \multicolumn{2}{|c|}{ Welimada } & IU3e \\
\hline Monaragala & IL1c & & & \\
\hline
\end{tabular}

*Source for non-sampled locations (Jayaweera, 1980); Officers of Departments of Forest, Wildlife Conservation and Indigenous Medicine.

\section{Morphological variation of Terminalia chebula}

Variations were observed in stem/trunk characters, leaf characters and fruit characters of $T$. chebula. In contrast, there were no observable variations in flower characters. The withintree variation for fruit characters was not significant $(p>0.01)$, while the between-trees 
variation was significant $(p<0.01)$ for fruit characters such as fruit shape and fruit size. Both between-and within-tree variations were significant $(p<0.01)$ in terms of leaf characters.

\section{Principal component analysis}

The first three Principal components (PC) obtained using all studied morphological characters explained $87.8 \%$ of the accumulated variation of $T$. chebula populations, which is sufficient to represent the overall variation of the total population. Eigen vector indicated that leaf area is the key variable for PC 1, chlorophyll, fruit diameter and longitudinal section of the fruit are the major contributors to PC 2 while the leaf perimeter and $\mathrm{DBH}$ were the key contributors to PC 3 .

\section{Hierarchical clustering with principal components}

The dendrogam obtained by hierarchical clustering of the first three principal components showed four distinct groups at a linkage distance of 1.26 (Fig1) in the population, ignoring two outliers. Leaf area was the most significant contributor to first principal component and clustering was primarily based on leaf characters of the plant. A greater contribution of fruit characters namely, fruit diameter and the longitudinal section of fruit, to the PC suggests a relationship between clusters and fruit characters. This phenomenon indicated that it is possible to group the $T$. chebula trees according to their fruit shapes. Unique characters of each cluster are given in Table 2.

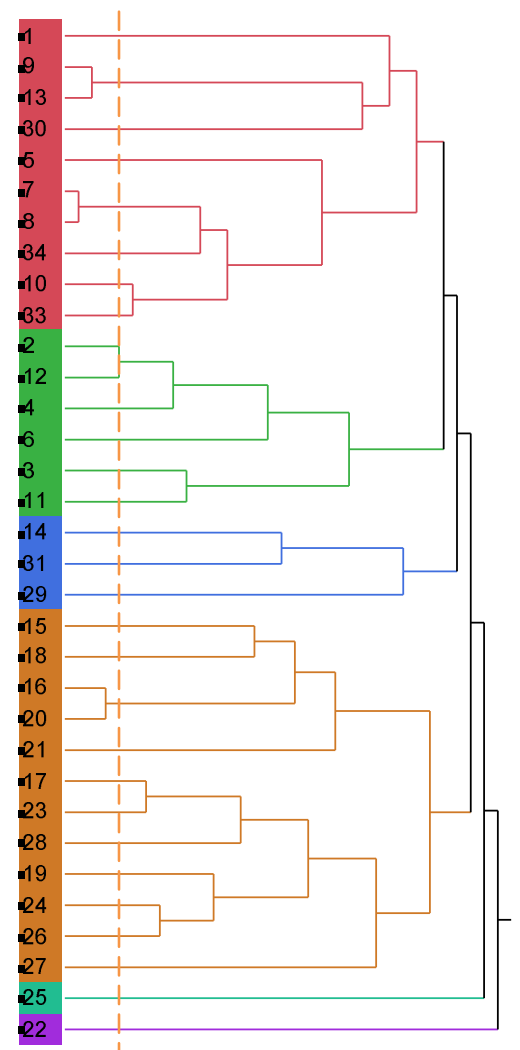

Fig.1. Dendrogram illustrating the four clusters obtained using first three principal components. 
Table 2. Unique characters of clusters in the dendrogram.

\begin{tabular}{|c|c|}
\hline Cluster & Unique characters \\
\hline Cluster 1 & Fruits are relatively large (average weight $=5.1 \mathrm{~g}$ per fruit ) \\
\hline Cluster 2 & $\begin{array}{l}\text { Same fruit shape ( } 3 \text {-Rohni), leaves are same size (average leaf area } \\
=27 \mathrm{~cm}^{2} \text { per leaf }\end{array}$ \\
\hline Cluster 3 & $\begin{array}{l}\text { Leaves are very large (average leaf area }=59.1 \mathrm{~cm}^{2} \text { per leaf), Fruits are } \\
\text { large (average weight }=5.3 \mathrm{~g} \text { per fruit) }\end{array}$ \\
\hline Cluster 4 & $\begin{array}{l}\text { Leaf shape is similar }(1-\text { Oval }) \text {, leaf orientation is nearly same }\left(52^{\circ}-66^{\circ}\right) \text {, } \\
\text { Tree vigour is high, All the plants are from Nilgala }\end{array}$ \\
\hline
\end{tabular}

\section{Implications on conservation and use of the species}

Terminalia chebula plants are more frequently found in the Nilgala and Dambana forest reserves compared to the other locations. These natural habitats are important for in-situ conservation of the species.

Being an economically important species, commercial cultivation of $T$. chebula could be promoted $e x$-situ as a conservation strategy. Further, commercial cultivation of the species would reduce the threat on natural populations due to collection of seeds and its impacts on natural regeneration. Four clusters identified during the study through morphological characterization are useful to streamline the medicinal usage of the plant or its parts and their chemical characterization.

\section{CONCLUSIONS}

Terminalia chebula trees are naturally distributed only in the Intermediate zone of Sri Lanka although, planted trees can be seen in all agro-ecological zones. The populations of $T$. chebula in Sri Lanka can be clustered into four groups based on their morphological characters. About $80 \%$ of the Nilgala population is grouped into one cluster suggesting a relationship between environmental parameters and the species. The within-tree variability for fruit characteristics was not significant $(p>0.01)$ while the between-tree fruit characters showed a significant variation $(\mathrm{p}<0.01)$.

\section{REFERENCES}

Ayurveda Department (2002). Compendium of medicinal plants: A Sri Lankan study. Vol II. Ayurvedic Department. pp233-237.

Handa, S.S., Rakesh, D.D. and Vasisht, K. (2006). Compendium of medicinal and aromatic plants: Vol II: The international centre for science and high technology - United Nations Industrial Development Organization (ICS-UNIDO), Ministry of foreign affairs, AREA Science Park, Padriciano 99, 34012 Trieste, Italy. pp177-188.

IBPGR (1980). Tropical fruit descriptors. International board for plant genetic resources. South Asia regional committee. Working group to review the tropical fruit descriptors and strategy for collection, evaluation, utilization and conservation. Bangkok. Thailand. 
Jayaweera, D.M.A. (1980). Medicinal plants (indigenous and exotic) used in Ceylon, part II: A publication of the National Science Council of Sri Lanka, Colombo, Sri Lanka. pp 36-37.

Philcox, D. (1997). A revised handbook to the Flora of Ceylon, Vol II. In: Dassanayake, M.D., and Frosberg, F.R., (Ed.). Combretaceae: A Publication of the National Herbarium, Peradeniya, Sri Lanka. pp 38-42.

Punyawardena, B.V.R. (2008) Rainfall pattern and agro-ecological regions of Sri Lanka (in Sinhala). Department of Agriculture, Peradeniya, Sri Lanka. pp. 25-125

Sneath, P.H.A. and Sokal, R.R. (1973). Numerical taxonomy, Freeman, San Francisco, CA, USA.

Ward, J.H. (1963). Hierarchical grouping to optimize an objective function, Journal of the American Statistical Association. 58, 236-244. 